Supporting Information

\title{
Metal Oxy-Hydroxides with A Hierarchical and Hollow Structure for Highly Efficient Solar-Thermal Water Evaporation
}

Zhi-Yong Luo ${ }^{a, b,+}$, Dong Wang ${ }^{a,+}$, Kai-Xuan Chen ${ }^{c}$, Lingqi Huang ${ }^{a, b}$, Xiangyang Liu ${ }^{a}$, Qi Zhang ${ }^{a}$, He Zhu ${ }^{a,}$, and Shiping Zhu ${ }^{a,{ }^{*}}$

a School of Science and Engineering, The Chinese University of Hong Kong, Shenzhen, Shenzhen, Guangdong, 518172, P.R. China.

${ }^{\mathrm{b}}$ University of Science and Technology of China, Hefei, Anhui, 230026, P.R.China.

${ }^{\mathrm{c}}$ Chair of Solid-State and Quantum Chemistry, Institute of Inorganic Chemistry, RWTH Aachen University, 52056, Aachen, Germany.

Email: zhuhe@cuhk.edu.cn, shipingzhu@cuhk.edu.cn

[+] These authors contributed equally to this work. 

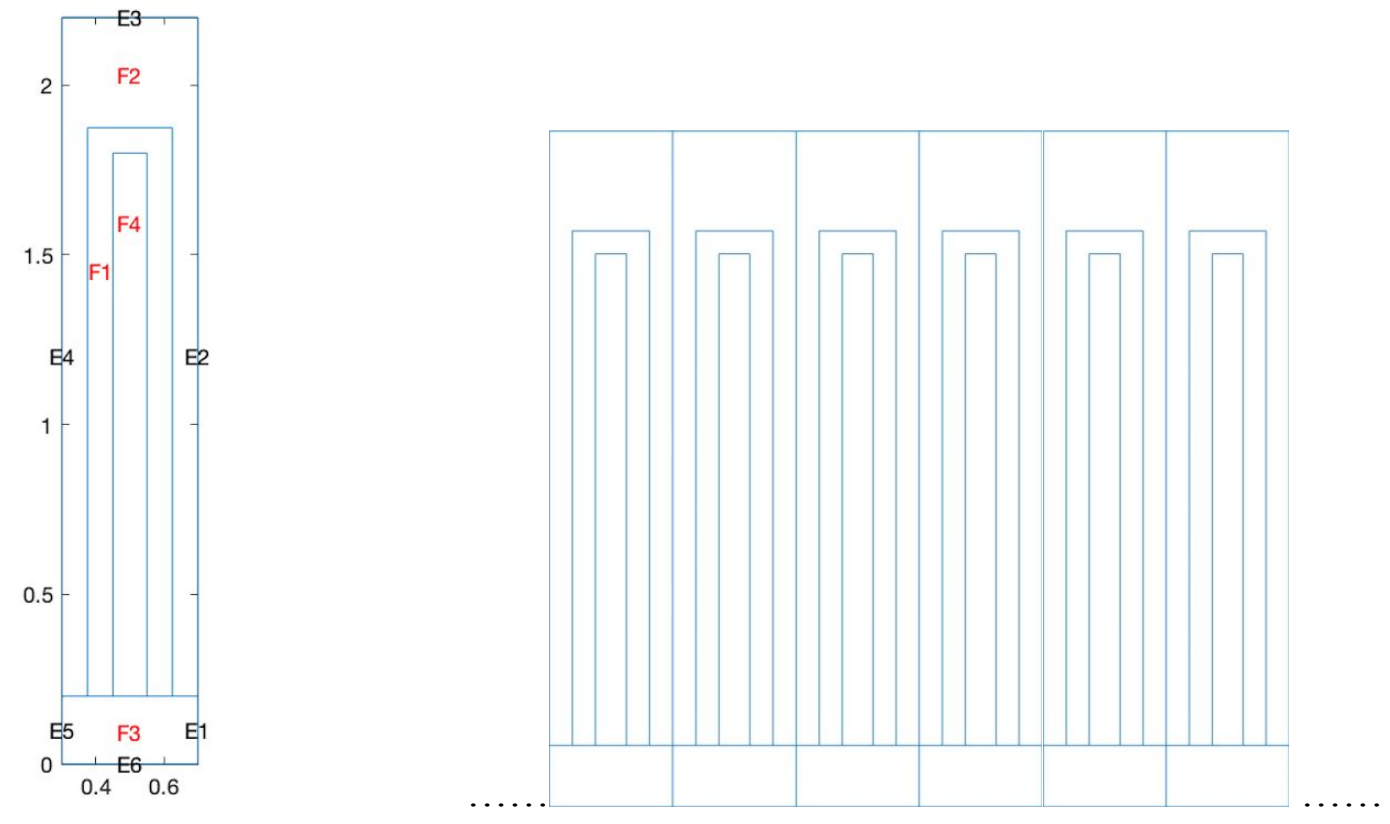

Figure S1. The approximate mathematical model of nanorod array.

To be specific, we assume the environment is a periodic arrangement of the material, so we consider the domain as a periodic extension of the domain shown in Figure S1. 


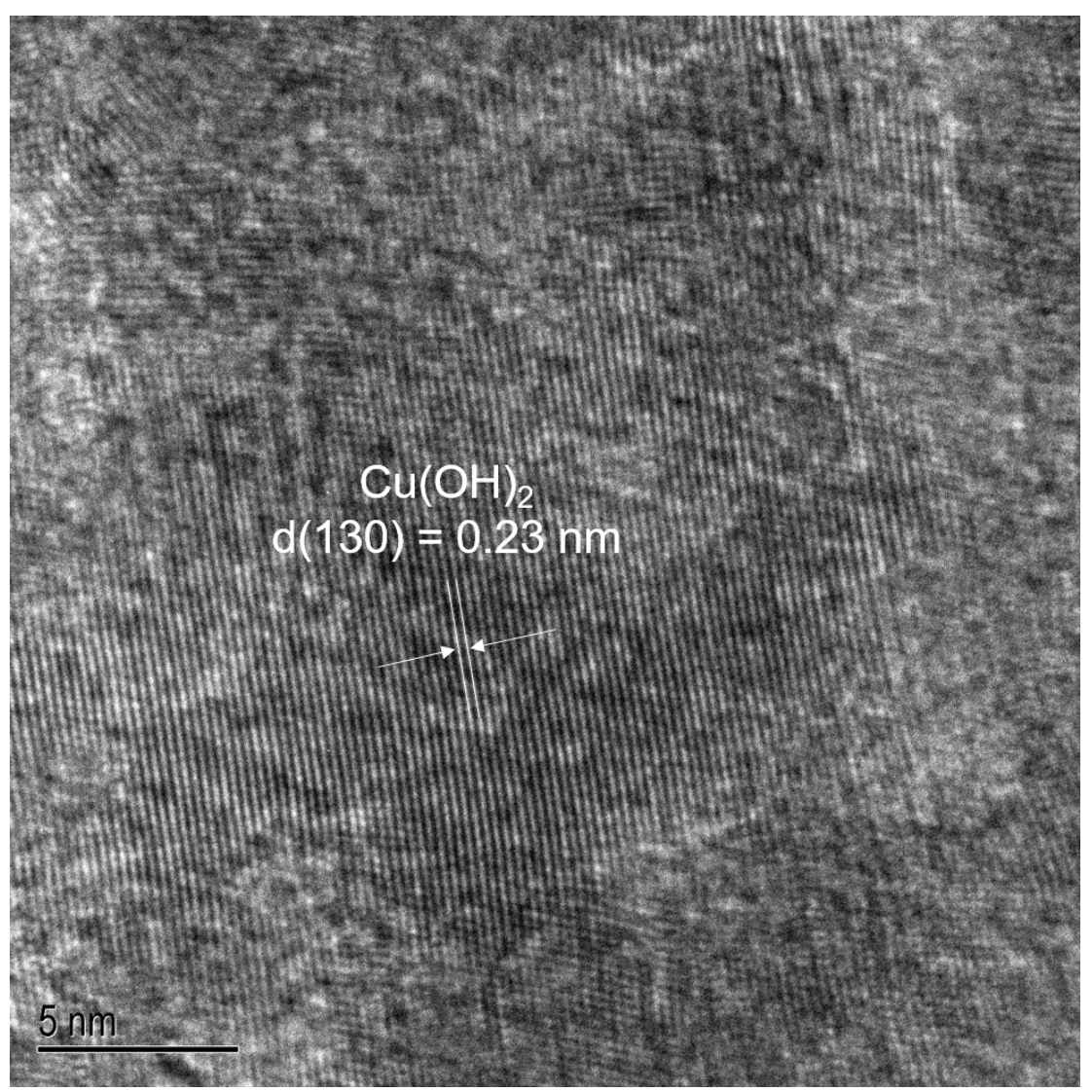

Figure S2. The HRTEM image of $\mathrm{Cu}(\mathrm{OH})_{2}$ nanorod.

The lattice distance of $0.23 \mathrm{~nm}$ was attributed to the (130) plane of $\mathrm{Cu}(\mathrm{OH})_{2}(\mathrm{JCPDS}-80-0656)$. 

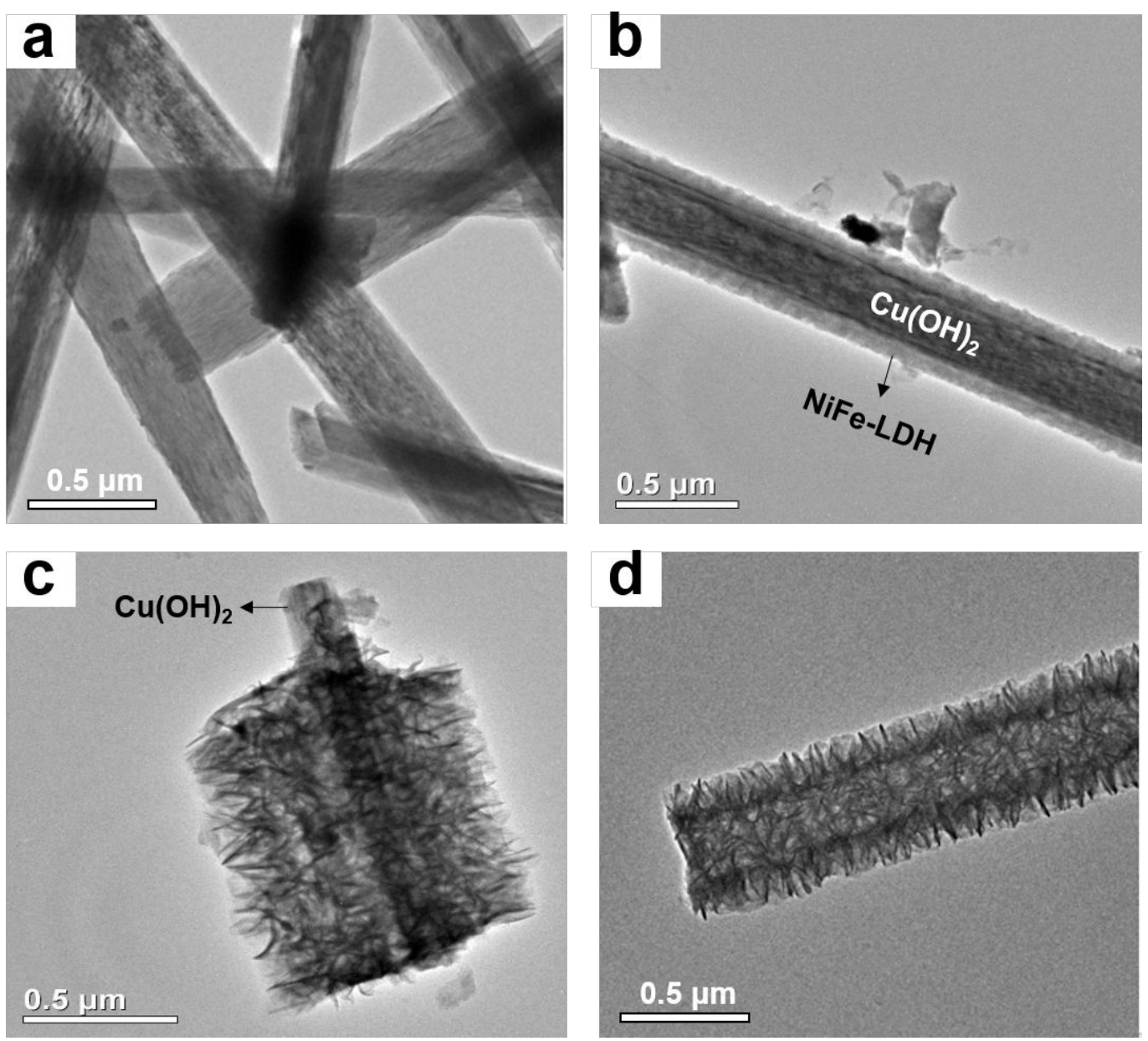

Figure S3. (a) TEM image of $\mathrm{Cu}(\mathrm{OH})_{2}$ nanorods. (b-d) TEM images of samples after electrodepositing NiFe-LDH for 100, 200 and 300 s, respectively.

After NiFe-LDH deposition, the structure evolved from $\mathrm{Cu}(\mathrm{OH})_{2}-\mathrm{NiFe}-\mathrm{LDH}$ core-shell structure to hollow structure due to the cation-exchange mechanism. The HNLC was assembled from nanosheets. 


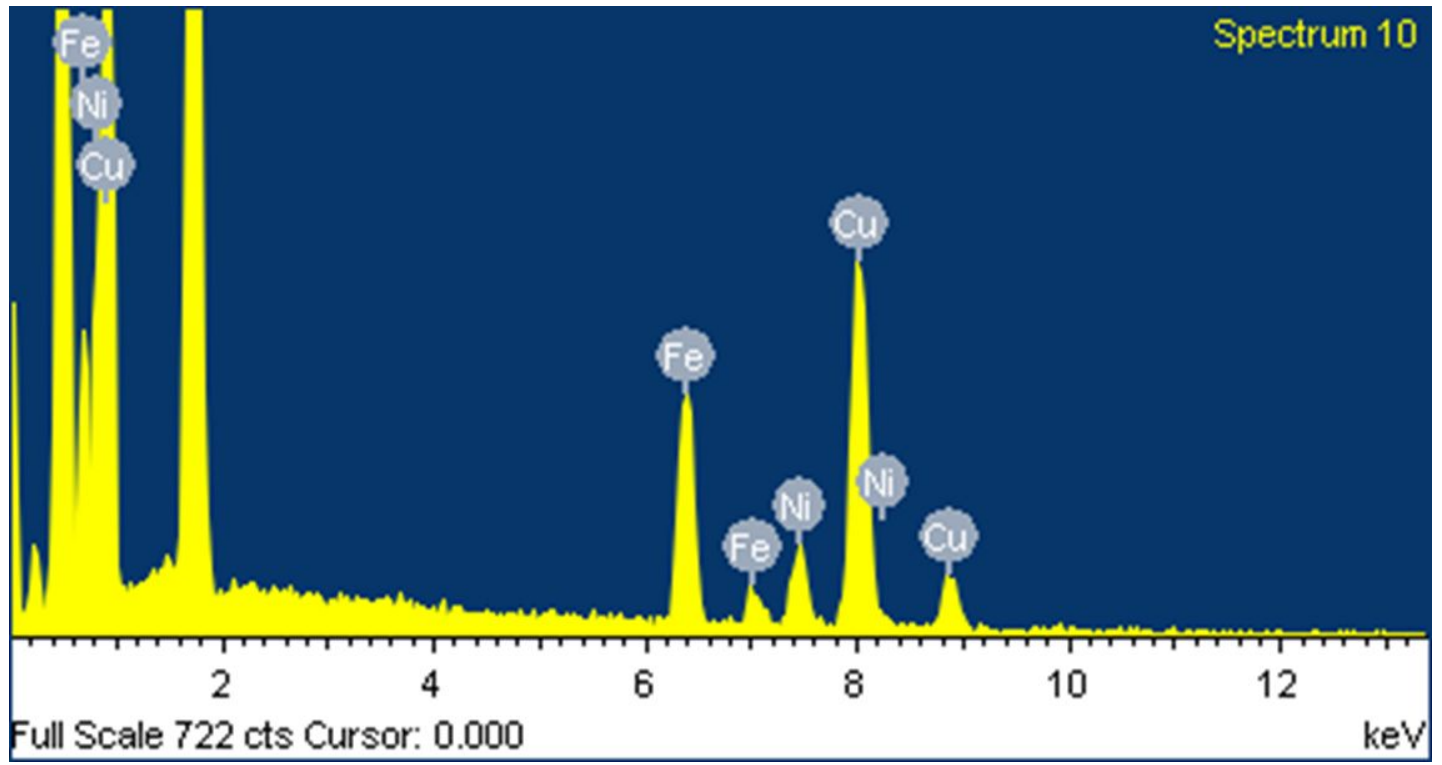

Figure S4. EDX characterization of HNLC.

The EDX result reveals the presence of $\mathrm{Cu}$, Ni and $\mathrm{Fe}$ in $\mathrm{HNLC}$, meaning $\mathrm{Cu}(\mathrm{OH})_{2}$ and $\mathrm{NiFe}-$ LDH co-existed in HNLC. The ratios of $\mathrm{Cu}, \mathrm{Ni}$ and $\mathrm{Fe}$ are $63.32 \mathrm{at} \%, 12.52 \mathrm{at} \%$ and $24.16 \mathrm{at} \%$, respectively. 


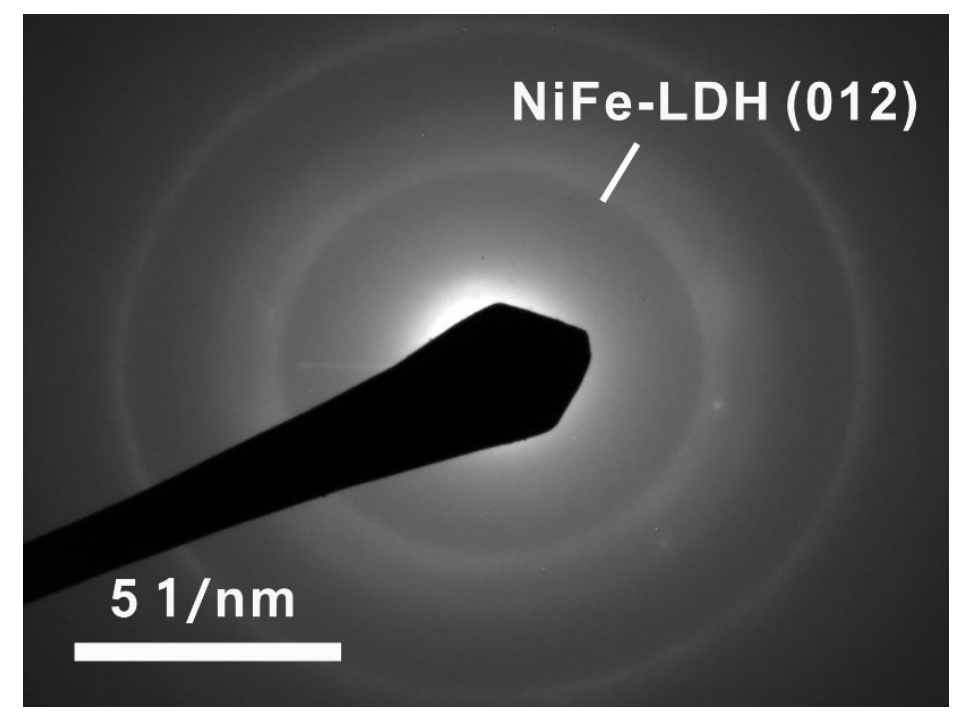

Figure S5. SAED analysis of E-HNLC.

The SAED result of E-HNLC reveals the crystal structure of NiFe-LDH in E-HNLC remained unchanged after electrochemical activation. 


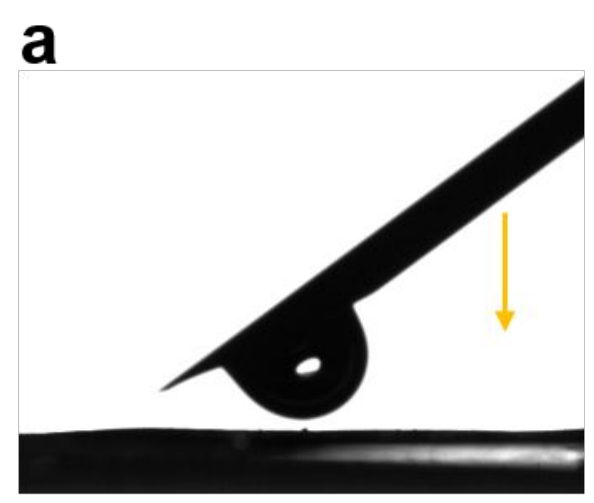

b
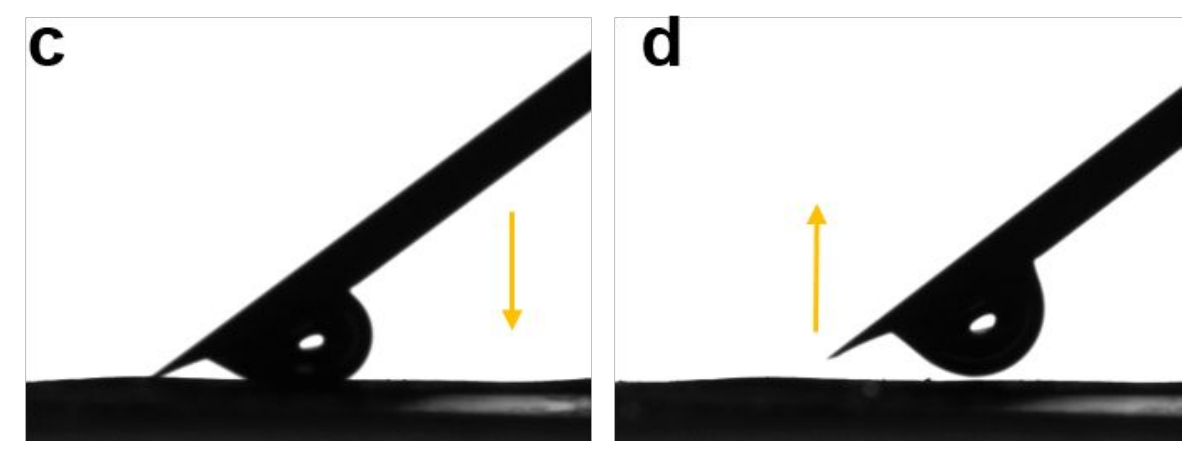

Figure S6. (a) - (d) The dynamic adhesion test of oil (hexane) to E-HNLC.

The dynamic adhesion test of oil to E-HNLC reveals its excellent anti-fouling property against oil. 


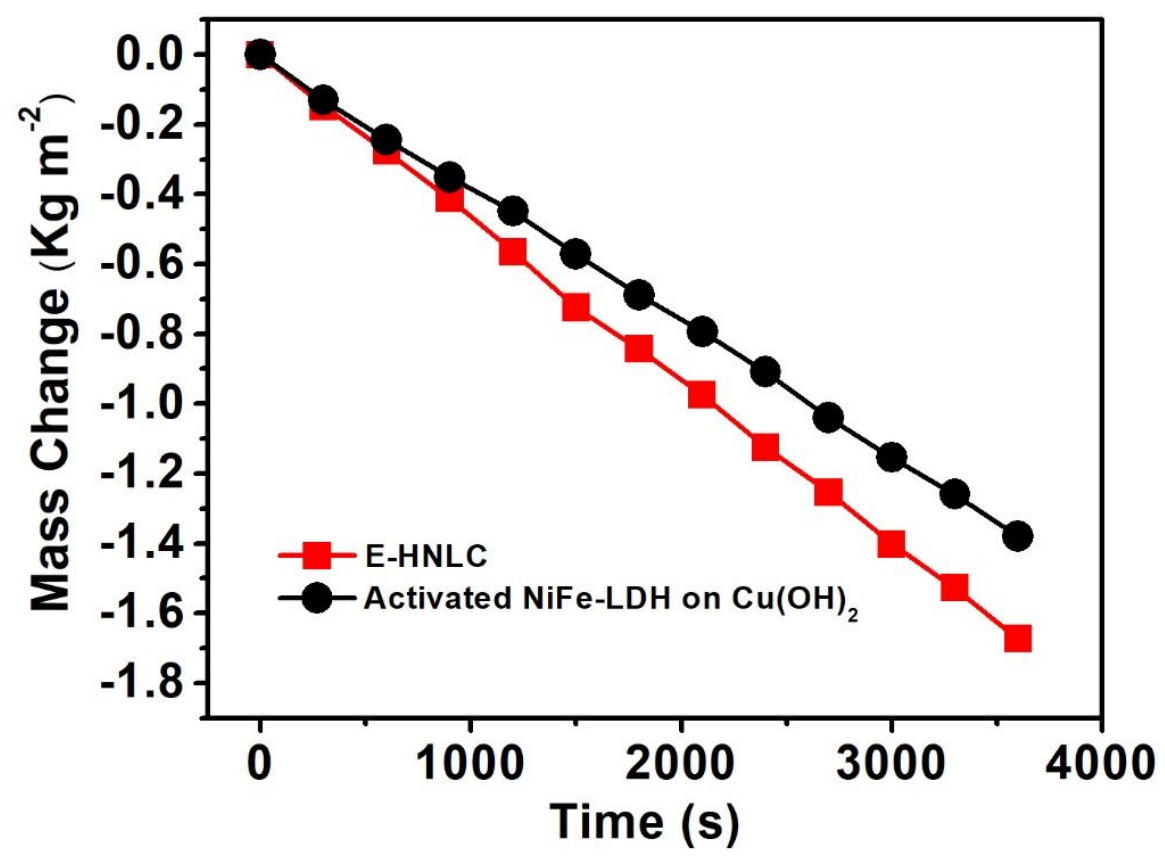

Figure S7. Typical curves of time-dependent mass change of E-HNLC with hollow structure and activated $\mathrm{NiFe}-\mathrm{LDH}$ on $\mathrm{Cu}(\mathrm{OH})_{2}$ with core-shell structure under 1 sun illumination

To demonstrate the superiority of hollow structure for solar-thermal water evaporation, we compared the solar-thermal water evaporation rate of E-HNLC with hollow structure and activated $\mathrm{NiFe}-\mathrm{LDH}$ on $\mathrm{Cu}(\mathrm{OH})_{2}$ with core-shell structure under 1 sun illumination. In this controlled experiment, the actived $\mathrm{NiFe}-\mathrm{LDH}$ on $\mathrm{Cu}(\mathrm{OH})_{2}$ was obtained by electrochemically depositing NiFe-LDH onto the surface of $\mathrm{Cu}(\mathrm{OH})_{2}$ for $100 \mathrm{~s}$ (see Figure $\mathrm{S} 3 \mathrm{~b}$ ) and followed by electrochemical activation. As a result, the evaporation rate of E-HNLC $\left(1.65 \mathrm{~kg} \mathrm{~m}^{-2} \mathrm{~h}^{-1}\right)$ is much higher than that of activated NiFe-LDH on $\mathrm{Cu}(\mathrm{OH})_{2}\left(1.38 \mathrm{~kg} \mathrm{~m}^{-2} \mathrm{~h}^{-1}\right)$. 


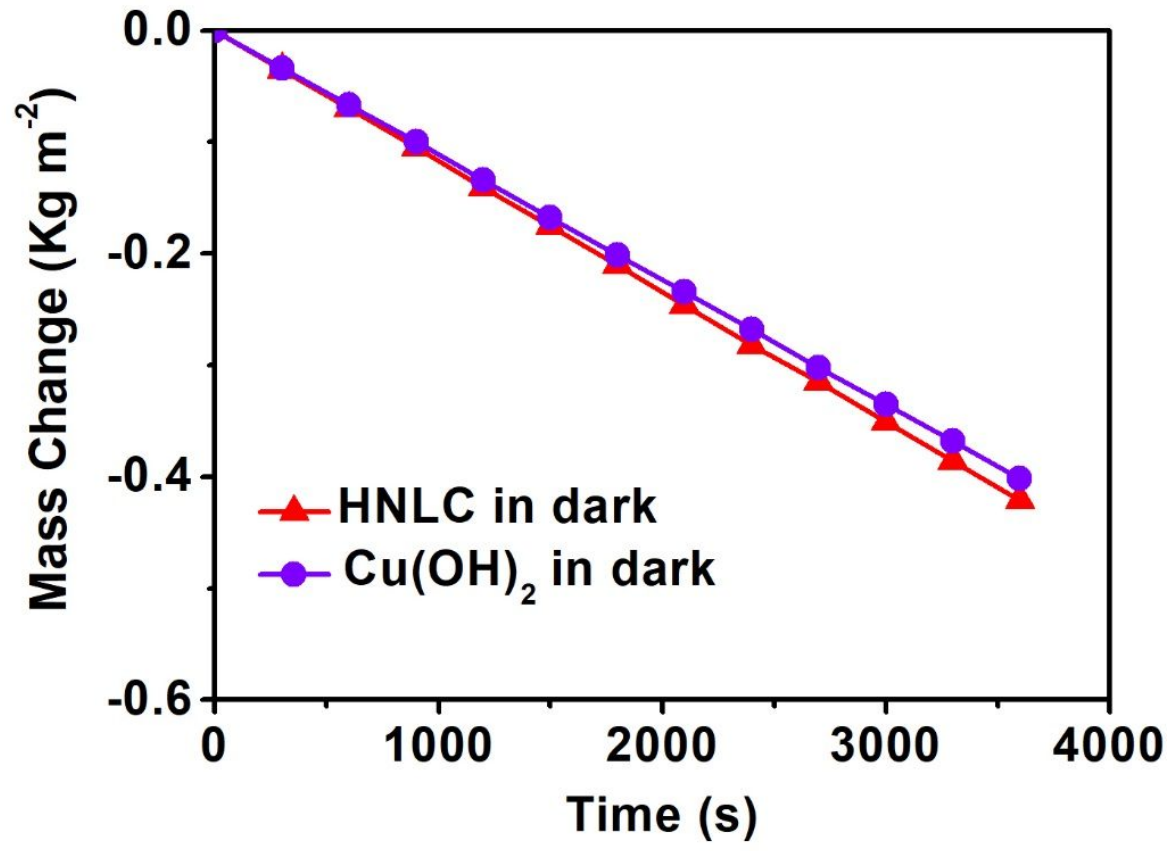

Figure S8. Time-dependent mass change of $\mathrm{Cu}(\mathrm{OH})_{2}$ and $\mathrm{HNLC}$ employed in water evaporation in dark.

The water evaporation rate of $\mathrm{Cu}(\mathrm{OH})_{2}$ and $\mathrm{HNLC}$ in dark were 0.4 and $0.42 \mathrm{~kg} \mathrm{~m}^{-2} \mathrm{~h}^{-1}$, respectively. 


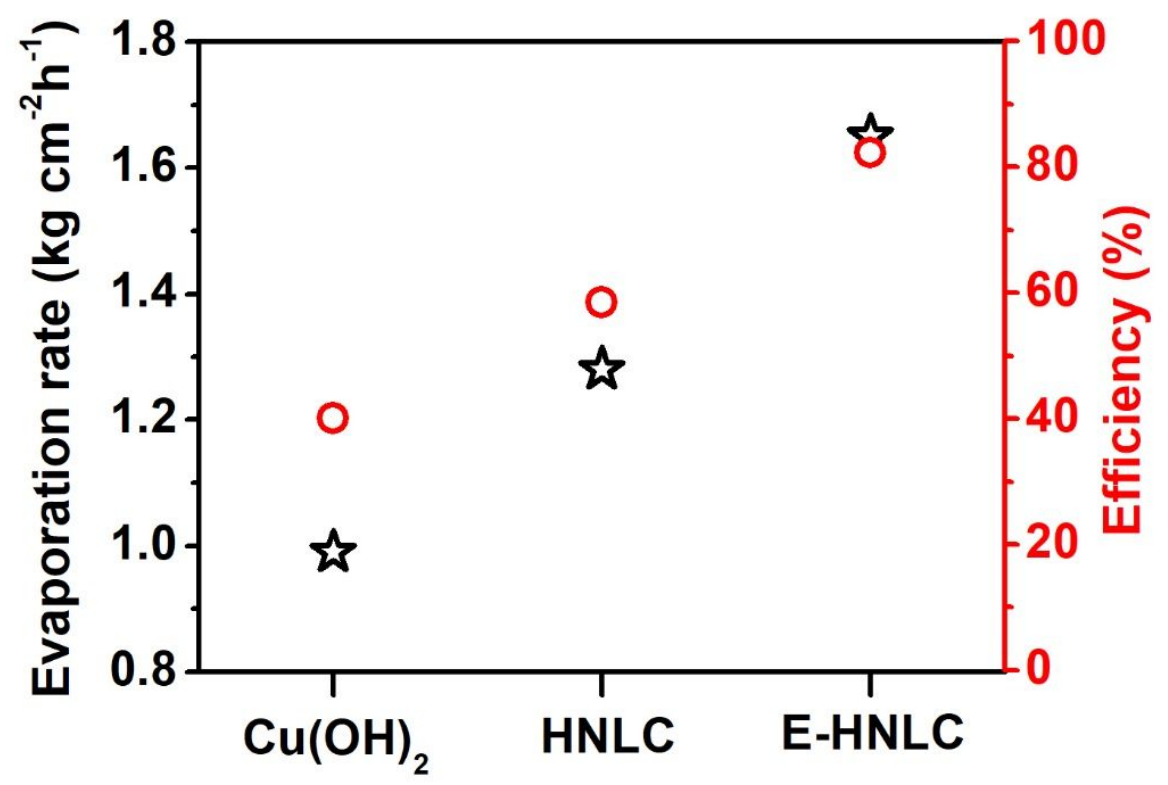

Figure S9. The solar-thermal water evaporation rate and the corresponding solar-to-thermal conversion efficiency of $\mathrm{Cu}(\mathrm{OH})_{2}, \mathrm{HNLC}$ and E-HNLC, respectively.

The water evaporation rate of $\mathrm{Cu}(\mathrm{OH})_{2}, \mathrm{HNLC}$ and E-HNLC were measured to be $0.99,1.28$ and $1.65 \mathrm{~kg} \mathrm{~m}^{-2} \mathrm{~h}^{-1}$, respectively. The solar-thermal conversion efficiency of $\mathrm{Cu}(\mathrm{OH})_{2}, \mathrm{HNLC}$ and E-HNLC were calculated to be $40.1 \%, 58.5 \%$ and $82.3 \%$ under 1 sun illumination, respectively. The calculation method of solar-thermal conversion efficiency can be found in the reported literatures. ${ }^{1}$ 
Table S1. Comparison of solar-thermal water evaporation performance of some recently reported materials (1 sun).

\begin{tabular}{|c|c|c|c|}
\hline No. & Materials & $\begin{array}{l}\text { Evaporation } \\
\text { rate } \\
\left(\mathrm{kg} \mathrm{m}^{-2} \mathrm{~h}^{-1}\right)\end{array}$ & References \\
\hline 1 & PVA/PPy gels & 3.2 & Nat. Nanotechnol. 2018, 13, $489^{2}$ \\
\hline 2 & $\begin{array}{l}\text { 1D-O-doped } \mathrm{MoS}_{2-\mathrm{x}} \\
\text { nanosheets }\end{array}$ & 2.5 & Adv. Mater. 2020, 32, e20015443 \\
\hline 3 & $\begin{array}{l}\text { Black Au membrane } \\
\text { (3 layer) }\end{array}$ & 1.8 & Nat. Commun. 2015, 6, $10103^{4}$ \\
\hline 4 & E-HNLC & 1.65 & This work \\
\hline 5 & $\begin{array}{l}\text { MOF-based } \\
\text { hierarchical structures }\end{array}$ & 1.5 & Adv. Mater. 2019, 31, e18082495 \\
\hline 6 & Carbonized mushroom & 1.475 & Adv. Mater. 2017, 29, $1606762^{1}$ \\
\hline 7 & $\begin{array}{l}\text { 3D honeycomb } \\
\text { ceramic plate }\end{array}$ & 1.45 & Nano Energy 2019, 60, $222^{6}$ \\
\hline 8 & $\begin{array}{l}\text { Nanostructured Ni- } \\
\mathrm{NiO}_{x} / \mathrm{Ni} \text { foam }\end{array}$ & 1.41 & J. Mater. Chem. A 2019, 7, $8485^{7}$ \\
\hline 9 & $\begin{array}{l}\text { Plasma-made } \\
\text { graphene } \\
\text { nanostructures }\end{array}$ & 1.314 & $\begin{array}{l}\text { ACS Appl. Mater. Interfaces } \mathbf{2 0 2 0} \text {, } \\
12,38512^{8}\end{array}$ \\
\hline 10 & $\begin{array}{l}\text { Graphene oxide-based } \\
\text { film }\end{array}$ & 1.21 & $\begin{array}{l}\text { Proc. Natl. Acad. Sci. US A 2016, } \\
113,13953^{9}\end{array}$ \\
\hline 11 & $\begin{array}{l}\text { Exfoliated } \\
\text { graphite/carbon foam }\end{array}$ & 1.2 & Nat. Commun. 2014, 5, $4449^{10}$ \\
\hline 12 & Origami system & 1.16 & Chem. Eng. J. 2019, 356, $869^{11}$ \\
\hline
\end{tabular}




\section{References}

1. Xu, N.; Hu, X.; Xu, W.; Li, X.; Zhou, L.; Zhu, S.; Zhu, J., Mushrooms as Efficient Solar Steam-Generation Devices. Adv. Mater. 2017, 29, 1606762.

2. Zhao, F.; Zhou, X.; Shi, Y.; Qian, X.; Alexander, M.; Zhao, X.; Mendez, S.; Yang, R.; Qu, L.; Yu, G., Highly Efficient Solar Vapour Generation Via Hierarchically Nanostructured Gels. Nat. Nanotechnol. 2018, 13, 489-495.

3. Lu, Q.; Shi, W.; Yang, H.; Wang, X., Nanoconfined Water-Molecule Channels for High-Yield Solar Vapor Generation under Weaker Sunlight. Adv. Mater. 2020, 32, e2001544.

4. Bae, K.; Kang, G.; Cho, S. K.; Park, W.; Kim, K.; Padilla, W. J., Flexible Thin-Film Black Gold Membranes with Ultrabroadband Plasmonic Nanofocusing for Efficient Solar Vapour Generation. Nat. Commun. 2015, 6, 10103.

5. Ma, Q.; Yin, P.; Zhao, M.; Luo, Z.; Huang, Y.; He, Q.; Yu, Y.; Liu, Z.; Hu, Z.; Chen, B.; Zhang, H., MOF-Based Hierarchical Structures for Solar-Thermal Clean Water Production. Adv. Mater. 2019, 31, e1808249.

6. Shi, L.; Shi, Y.; Zhuo, S.; Zhang, C.; Aldrees, Y.; Aleid, S.; Wang, P., Multi-Functional 3d Honeycomb Ceramic Plate for Clean Water Production by Heterogeneous PhotoFenton Reaction and Solar-Driven Water Evaporation. Nano Energy 2019, 60, 222-230.

7. Wu, D.; Qu, D.; Jiang, W.; Chen, G.; An, L.; Zhuang, C.; Sun, Z., Self-Floating Nanostructured Ni-Niox/Ni Foam for Solar Thermal Water Evaporation. J. Mater. Chem. A 2019, 7, 8485-8490.

8. Wu, S.; Gong, B.; Yang, H.; Tian, Y.; Xu, C.; Guo, X.; Xiong, G.; Luo, T.; Yan, J.; Cen, K.; Bo, Z.; Ostrikov, K. K.; Fisher, T. S., Plasma-Made Graphene Nanostructures with Molecularly Dispersed F and Na Sites for Solar Desalination of Oil-Contaminated Seawater with Complete in-Water and in-Air Oil Rejection. ACS Appl. Mater. Interfaces 2020, 12, 38512-38521.

9. Li, X.; Xu, W.; Tang, M.; Zhou, L.; Zhu, B.; Zhu, S.; Zhu, J., Graphene Oxide-Based Efficient and Scalable Solar Desalination under One Sun with a Confined 2d Water Path. Proc. Natl. Acad. Sci. U S A 2016, 113, 13953-13958.

10. Ghasemi, H.; Ni, G.; Marconnet, A. M.; Loomis, J.; Yerci, S.; Miljkovic, N.; Chen, G., Solar Steam Generation by Heat Localization. Nat. Commun. 2014, 5, 4449.

11. Xu, Y.; Ma, J.; Liu, D.; Xu, H.; Cui, F.; Wang, W., Origami System for Efficient Solar Driven Distillation in Emergency Water Supply. Chem. Eng. J. 2019, 356, 869-876. 
